\title{
Enhancing Seismic Capacity of Pile-Supported Wharves Using Yielding Dampers
}

\author{
Seyed Amin Mousavi and Khosrow Bargi \\ School of Civil Engineering, University of Tehran, P.O. Box 11365-4563, Tehran, Iran \\ Correspondence should be addressed to Seyed Amin Mousavi; s.a.mousavi@ut.ac.ir
}

Received 15 February 2013; Revised 5 May 2013; Accepted 13 May 2013

Academic Editor: Domenico Bruno

Copyright ( 2013 S. A. Mousavi and K. Bargi. This is an open access article distributed under the Creative Commons Attribution License, which permits unrestricted use, distribution, and reproduction in any medium, provided the original work is properly cited.

This paper presents a numerical study on the seismic response of pile-supported wharves equipped with metallic yielding dampers. Using 20 ground acceleration records, the contribution of the yielding damper is examined, and its main parameters are optimized through a parametric study. In the current study, considering coupling effects of different parameters, a new optimization procedure is proposed. The obtained results indicate that the stability condition of the retaining wall (quay wall) behind the wharf, period of the soil-wharf system, and also maximum allowable ductility ratio of the damper are the key factors affecting the optimum damper parameters. A simplified design guideline is proposed for either the design or the retrofit purposes followed by a numerical assessment to evaluate the contribution of the proposed damper on the seismic behavior of a typical pile-supported wharf. The obtained results show that yielding dampers, through their nonlinear behavior, can dissipate a large portion of seismic input energy and mitigate piles damages which have been observed in earlier earthquake events.

\section{Introduction}

During an earthquake event liquefaction of saturated loose sandy soils and excessive piles drifts make the most common causes of damages to pile-supported wharves. Therefore, in absence of liquefaction conditions, pile drift can be considered as a suitable indicator in order to evaluate performance of wharves under seismic events. Some techniques, which rely on stiffness increasing, such as inclined piles, have been investigated in earlier studies by Gerolymos et al. [1] and Poulos [2], as a method to reduce lateral displacements of pile-supported wharves. Inclined piles have two main drawbacks, high construction costs and punching failures in their connections. As reported by Oyenuga et al. [3], however, the punching failure problem can be moderated using a new design approach for pile-deck connections. Lehman et al. [4] have also improved performance of pile-wharf connections. In another study a novel stone column has been proposed by Mageau and Chin [5] to improve seismic behavior of wharves. Using passive control techniques, this study tried to improve the seismic behavior of pile-supported wharves.
Nowadays passive control methods have gained more attention in order to mitigate natural or man-made structural vibrations. Some of these passive techniques have been briefly described by Soong and Dargush [6]. Earlier studies on passive control techniques have been commonly restricted to long period structures, such as tall buildings, long-span bridges, and offshore jacket platforms, to the authors' knowledge, passive energy dissipation devices have not been investigated earlier for wharves. Among various passive dampers, metallic yielding damper seems to be more appropriate as yielding dampers are easy to manufacture and need no specific maintenance. To date, many studies have been devoted to yielding dampers [7-10]. However, they have mainly focused on building structures in which dampers were in conjunction with chevron braces.

Nowadays, with increasing ship sizes, berth deepening seems to be inevitable and consequently a new generation of pile-supported wharves would have relatively larger periods. Accordingly, the focus of this study is mainly on flexible wharves. As depicted in Figure 1, stability conditions of the retaining wall would dictate the maximum allowable yielding 


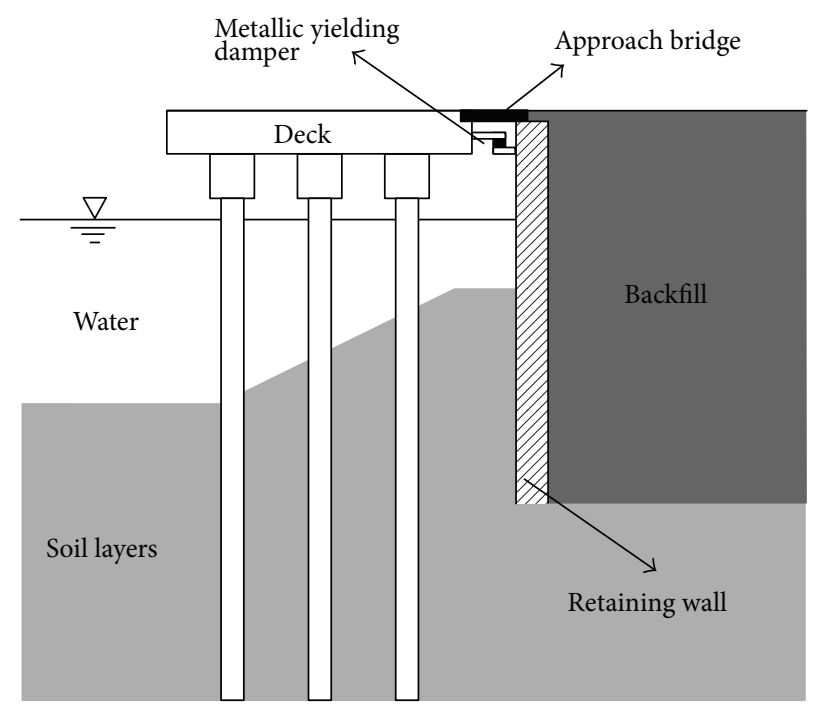

(a)

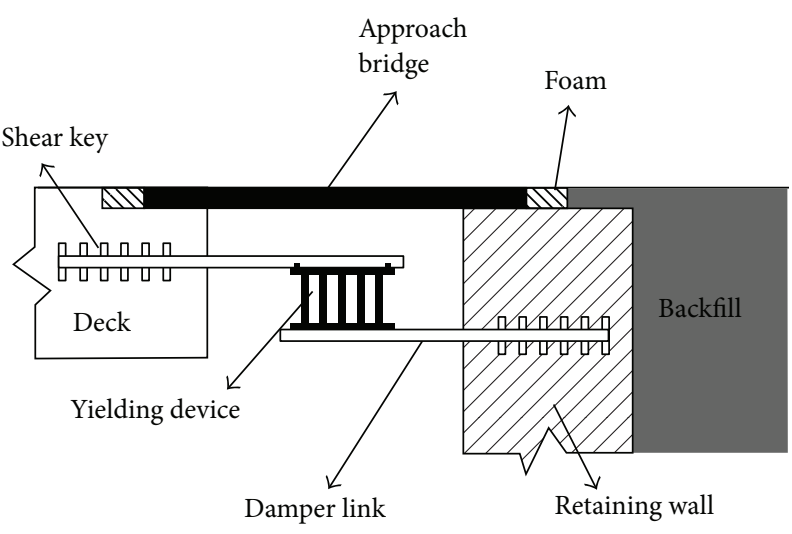

(b)

FIGURE 1: Damper-wharf system.

force of the damper. Note that the yielding force of the damper can be adjusted to very small values. In other words, during a seismic event, damper forces can be tuned to be far less than those imposed by other sources, such as backfill soil pressure or inertial force of the retaining wall. As a result, the damper can be designed as if it has virtually no destructive effect on the retaining wall. It should be elaborated that the retaining wall can be of any type, for example, gravity wall, caisson, sheet pile, and so forth. During this study, metallic yielding damper, metallic damper, yielding damper, and damper are all considered to have the same meaning and are used instead of each other.

\section{Scope of the Current Study}

The main objective of the present study is to mitigate seismicinduced responses of pile-supported wharves using metallic yielding dampers that were placed between the deck and the retaining wall (quay wall) in specific intervals along the shoreline, as illustrated in Figure 1. In the design procedure, it is very important to transmit the damper force to the ground within a safe load path. As a result, depending on residual capacity of the retaining wall, there is a restriction on the allowable yielding force of the damper. As shown in Figure 1, the damper includes two parts, the yielding device and the damper link. The damper link connects the yielding device to the wharf deck and the retaining wall. The link is very stiff due to its short lengths and can be assumed to be rigid. To optimize different parameters of the damper, sets of values for damper stiffness and yielding force are considered, and the contribution of the damper for each of them is evaluated.

\section{Optimization Procedure}

In the optimization process, four single degree of freedom (SDOF) systems with periods of $0.4 \mathrm{~s}, 0.6 \mathrm{~s}, 0.8 \mathrm{~s}$, and $1.0 \mathrm{~s}$ are adopted and subjected to 20 digitized ground acceleration records. It is assumed that, during an earthquake, displacements at the top of the retaining wall are the same as those at the base of the wharf, that is, sea bed. In other words, displacements at the free end of the damper element are the same as those at the base of the SDOF system, Figure 2. Accordingly, during the optimization process, the retaining wall is not modeled as there are numerous different walls with different dynamic characteristics, and it is not practical to consider all possible wall conditions. Besides, this simplification is reasonable as the period of the wharf is far above than that of wall-soil system, especially in the case of long period wharves which are the main concern of this study. As a result, the wall-soil system can be assumed to be rigid compared to the wharf. Besides, the sea bed is very close to the top of the retaining wall, and it is possible to assume that seismic waves hit these two points simultaneously. While there are some experimental evidence that validate the previous assumptions $[11,12]$, in the Numerical Assessment, validity of this assumption would be also investigated. Three values of $0.05,0.1$, and 0.2 are adopted for yielding force-deck weight ratio, that is, the ratio of the damper yielding force to weight of the SDOF system. In addition, for each SDOF system, different stiffness ratios, that is, ratio of the damper stiffness to the SDOF stiffness, are adopted according to the period of the SDOF system, as presented in Table 1. Stiffness ratios for each period are selected so that maximum ductility ratio of the damper falls in a reasonable range.

Note that a constant value of 0.03 is considered for the strain hardening ratio of the damper material. As reported by Xia and Hanson [7], strain hardening ratio has a little influence on the behavior of yielding dampers. Therefore, the strain hardening is excluded from the carried out parametric study. According to most codes of practice, such as OCDI [13], pile-supported wharves should be designed to remain mainly elastic during ultimate seismic excitations. As a result, 


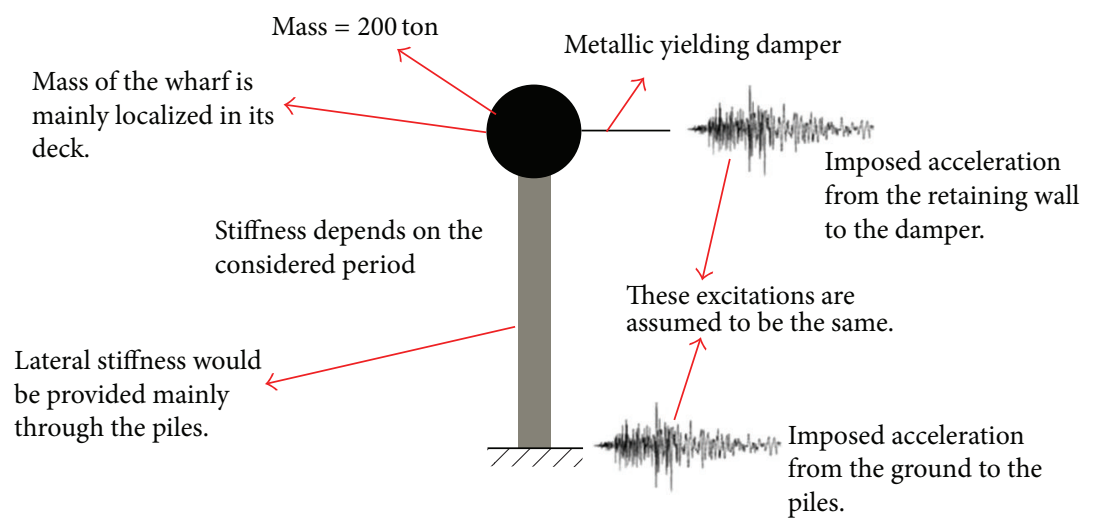

Figure 2: SDOF-damper system that is used in the optimization process. Mass $=200$ ton.

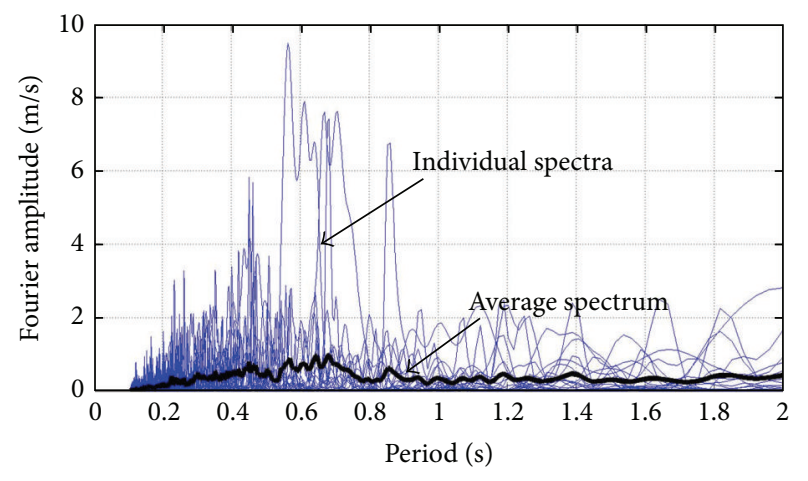

(a)

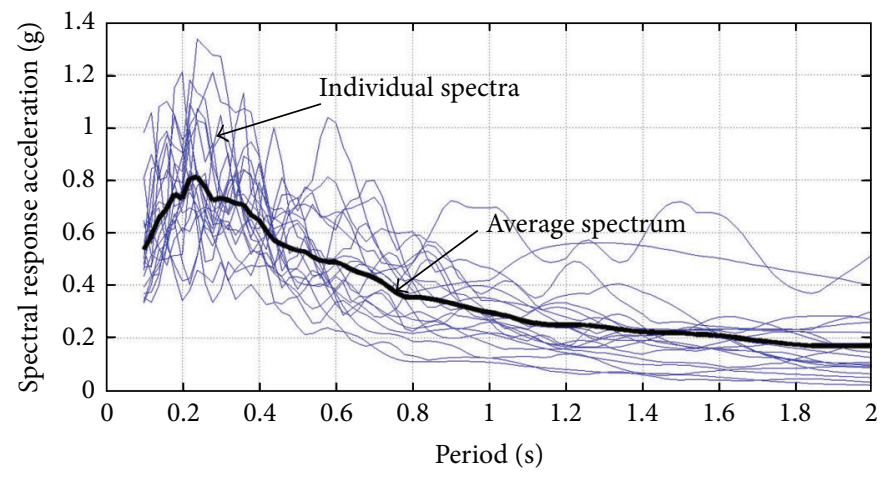

(b)

FIGURE 3: (a) Fourier spectra of the considered earthquakes and (b) 5\% damped spectral response acceleration of the considered earthquakes.

TABLE 1: Stiffness ratios which are considered for the SDOF systems.

\begin{tabular}{lc}
\hline Period of the SDOF system $(\mathrm{s})$ & Considered stiffness ratios \\
\hline 0.4 & $0.5,1,2,3,4$ \\
0.6 & $1,2,3,4,5$ \\
0.8 & $2,4,6,8,10$ \\
1 & $4,6,8,10,12$ \\
\hline
\end{tabular}

in the optimization procedure behaviors of the adopted SDOFs are assumed to be linear elastic.

\section{Record Selection}

As mentioned earlier, 20 digitized ground motion records, obtained from PEER database [14], are used in the optimization process. Adopted ground motions have magnitudes greater than 6 , and they are selected such that their averaged Fourier spectrum covers a broad band of periods of interest, that is, between $0.4 \mathrm{~s}$ and $1 \mathrm{~s}$. Characteristics of these ground motions are illustrated in the appendix. Moreover, frequency contents and acceleration response spectra of these 20 digitized ground acceleration records are shown in Figure 3. In the optimization process, all of these ground accelerations are scaled to $0.3 \mathrm{~g}$.
It should be elaborated that considering the lower PGAs is not necessary as the purpose of the damper is to remain elastic during moderate ground motions, and the main concern is only about extreme earthquake events. Note that selected ground accelerations are not explicitly scaled according to their response spectrum the as effect of their frequency contents on the damper parameters would be also investigated during the parametric study. According to Figure 3 and Table 1, however, it is clear that most of the considered earthquakes would impose a high level of resonance on the considered SDOF systems which is in agreement with the main philosophy of the spectrum-based scaling technique.

\section{Optimum Parameters of the Yielding Damper}

Optimization of the damper parameters is not a straightforward procedure. While higher damper stiffness would decrease deck displacement, it would also increase ductility demand of the damper. As a result, for a particular yielding force, higher stiffness values are not necessarily preferable due to the limitation on maximum allowable ductility of the damper. 


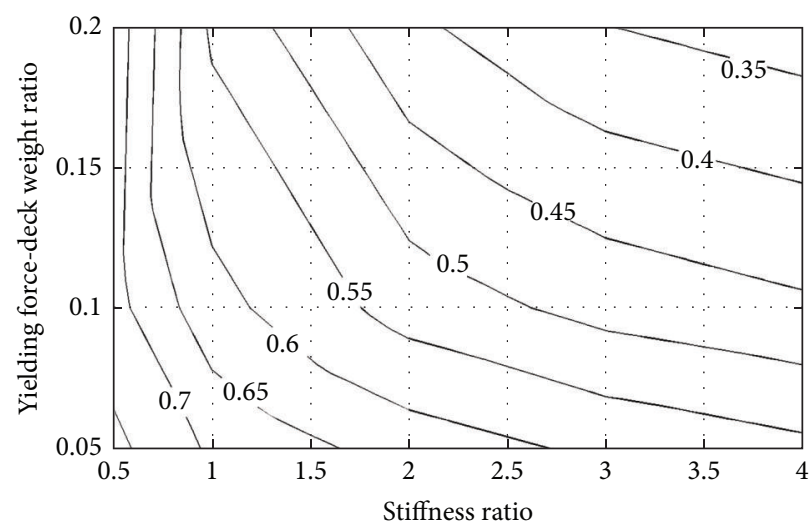

(a)

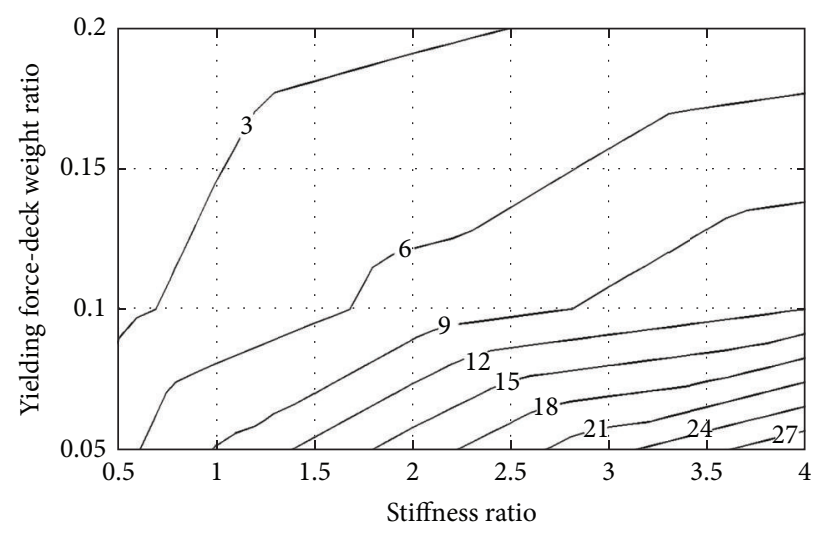

(b)

Figure 4: (a) Mean maximum displacement ratio and (b) mean maximum ductility ratio, period $=0.4 \mathrm{~s}$.

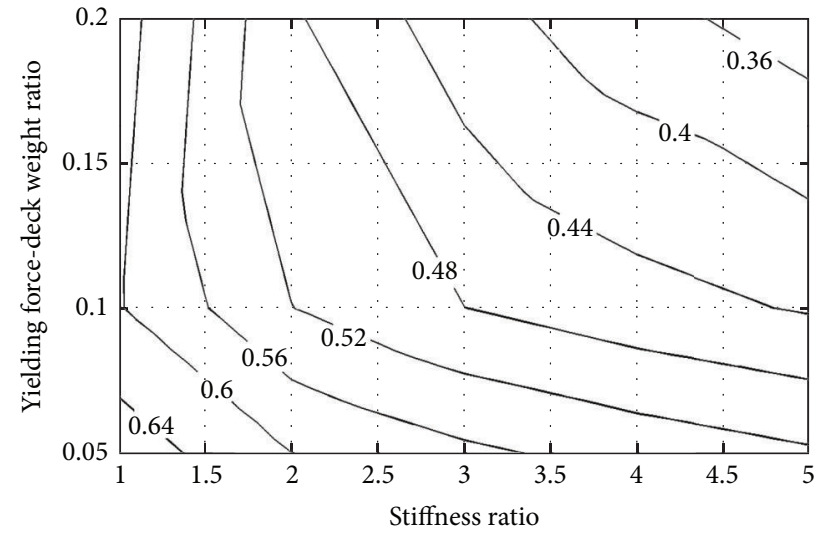

(a)

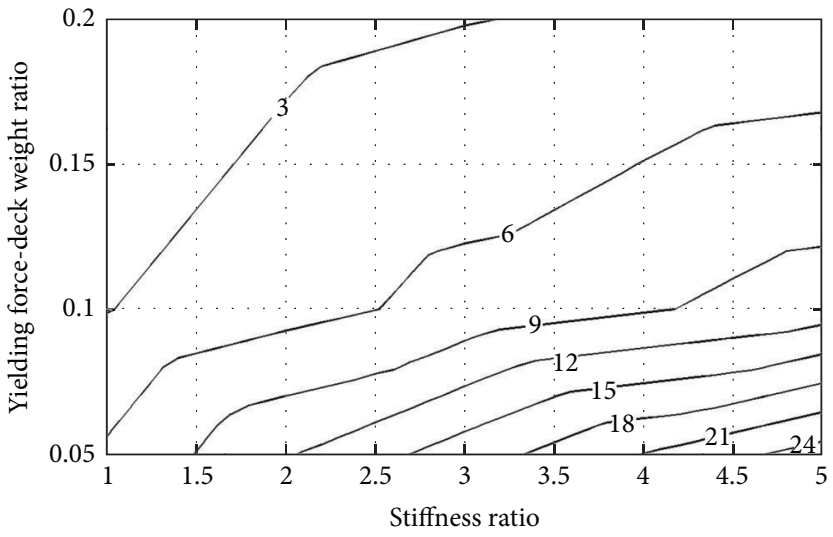

(b)

Figure 5: (a) Mean maximum displacement ratio and (b) mean maximum ductility ratio, period $=0.6 \mathrm{~s}$.

In this study mean maximum displacement ratio of each SDOF system is considered as the optimization index, and the mean maximum ductility ratio is also obtained for different values of the damper parameters. The results are shown in Figures 4, 5, 6, and 7. Required analysis is carried out by OpenSees, which has been developed by Mazzoni et al. [15]. Giuffre-Menegotto-Pinto model [15] is also adopted to simulate nonlinear behavior of the yielding damper. It should be clarified that, for each SDOF system, mean maximum displacement ratio is defined to be the mean of the maximum displacement ratios with and without damper, and mean maximum ductility ratio is the mean of the maximum damper ductility ratios for all 20 ground motion records. Note that the ductility ratio is the ratio of the damper deformation to its yielding deformation such that it cannot be smaller than one.

As stated earlier, the retaining wall would determine the allowable yielding force of the damper. Therefore, optimum values of the damper parameters depend on the period of the soil-wharf system, target maximum ductility ratio and stability conditions of the retaining wall. According to Figures $4-7$, in the case of short period wharves and for low stiffness ratios, by increasing the damper yielding force no improvement would occur on the damper efficiency. In general, the efficiency of the damper always increases by increasing the stiffness ratio; however, the maximum ductility ratio of the damper would also increase. Based on earlier experimental tests which have been reported by Xia and Hanson [7], value of about 6 is well suited for the maximum ductility ratio of a metallic yielding damper. As a result, other parameters should be selected such that maximum ductility ratio of the damper remains close to 6 .

Using resonance index concept, the effects of the frequency content on the damper efficiency and also on the maximum ductility ratio are investigated. Resonance index, as defined by Mousavi et al. [16], is the ratio of the Fourier amplitude corresponding to the period of the system to the maximum Fourier amplitude. Accordingly, if the value of the resonance index is close to one, the structure would experience a high level of resonance, and, if its value is close to zero, no noticeable resonance would occur. It should be pointed out that the term resonance in the current study refers to resonance of the first mode, and it would happen if the frequency content of the ground acceleration has high 


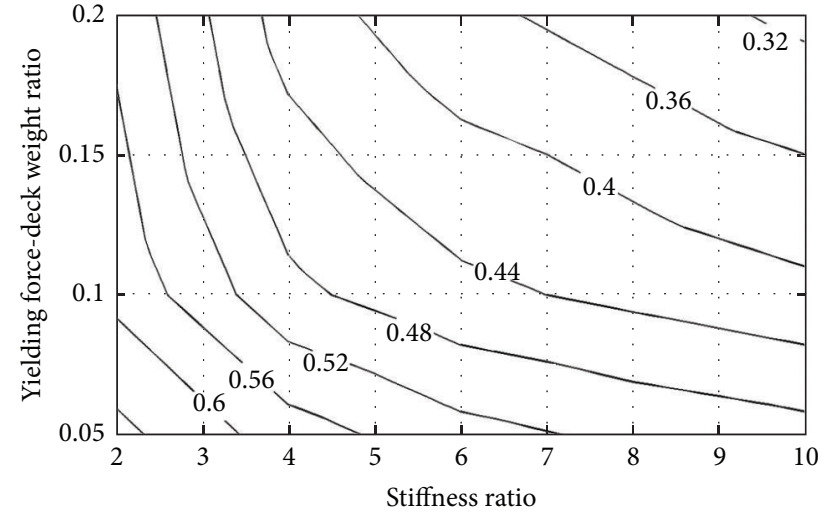

(a)

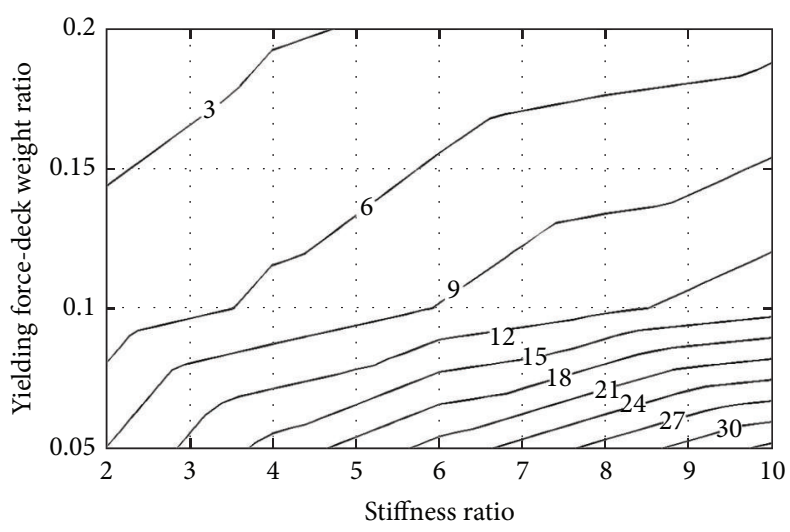

(b)

FIgURE 6: (a) Mean maximum displacement ratio and (b) mean maximum ductility ratio, period $=0.8 \mathrm{~s}$.

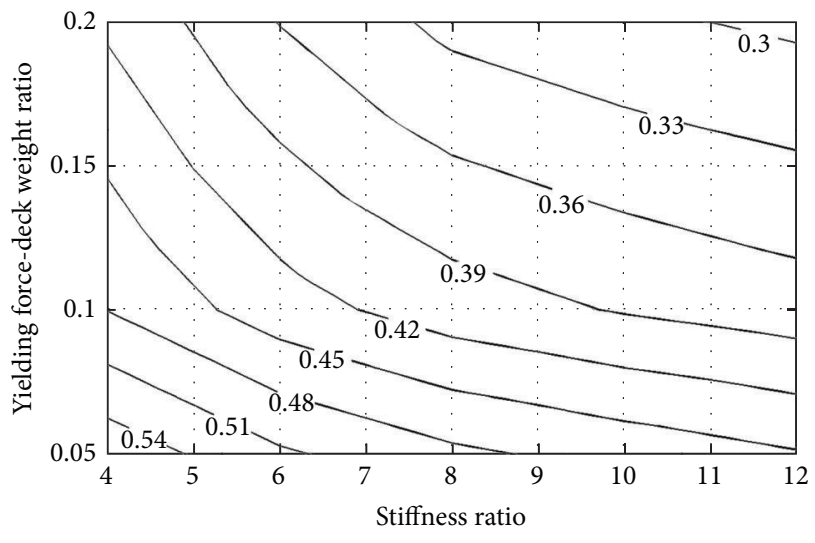

(a)

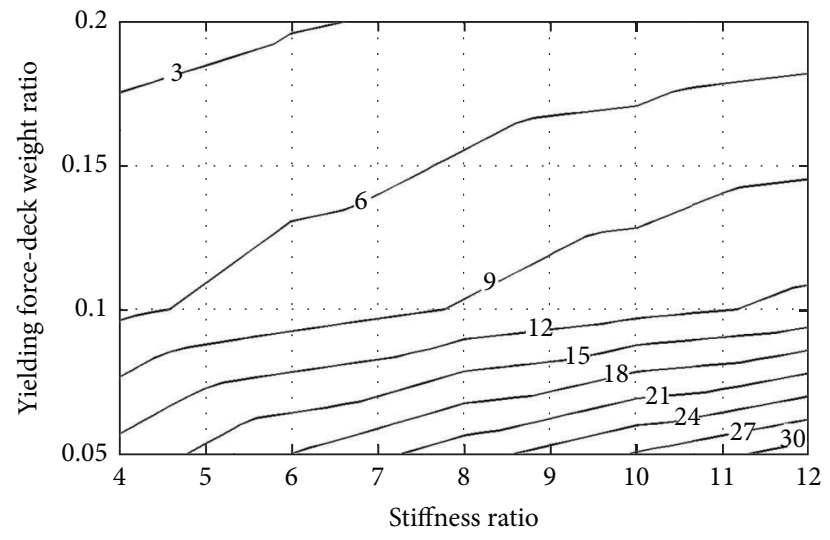

(b)

Figure 7: (a) Mean maximum displacement ratio and (b) mean maximum ductility ratio, period $=1.0 \mathrm{~s}$.

Fourier amplitudes in frequencies close to the fundamental frequency of the structure.

As illustrated in Figure 8, the resonance index has affected the damper efficiency and its maximum ductility ratio in an irregular manner. This is mainly due to nonlinear behavior of the damper and different pulse arrangements of the considered records. In other words, during an earthquake event, a wharf-damper system does not have a constant period, and its period would be a time, dependent parameter. From Figure 8 it is obvious that, in a general manner, by increasing the resonance index, the maximum ductility ratio increases, and the RMS (root mean square) displacement ratio decreases. This result is quite reasonable as in the resonance condition the damper would have a greater effect on the response and consequently would suffer greater damages (larger ductility demands).

According to the obtained results, using Matlab's Curve Fitting Toolbox [17], following relations for the stiffness ratio and its corresponding mean maximum displacement ratio can be proposed. Note that in proposed relations the allowable maximum ductility ratio is restricted to 6 :

$$
\mathrm{SR}=0.875 e^{14.2 \alpha} T,
$$

$$
\mathrm{MR}=(0.9-3.15 \alpha)(1-0.15 T),
$$

where SR is the stiffness ratio, MR represents the maximum displacement ratio, $\alpha$ denotes the yielding force-deck weight ratio, and $T$ stands for the period of the soil-wharf system (without damper).

In the case of yielding dampers, structural response would be reduced due to two reasons: (a) the energy dissipation capability of the damper and (b) stiffness increasing due to stiffness of the damper. While, in conventional methods [6, 18 ], both of the previous effects have been considered in estimating the equivalent viscous damping, in this study a new approach is proposed for evaluating the equivalent viscous damping. In this method, using the maximum displacement ratio, MR, and relevant response spectra, such as those proposed in FEMA-356 [19], the equivalent viscous damping can be estimated. According to the definition of MR, it is possible to rewrite it as follows:

$$
\mathrm{MR}=\frac{S_{a_{\mathrm{eq}}}}{S_{a}},
$$

where $S_{a_{\mathrm{eq}}}$ and $S_{a}$ are the spectral response accelerations of the wharf with and without damper, respectively. Having MR and 


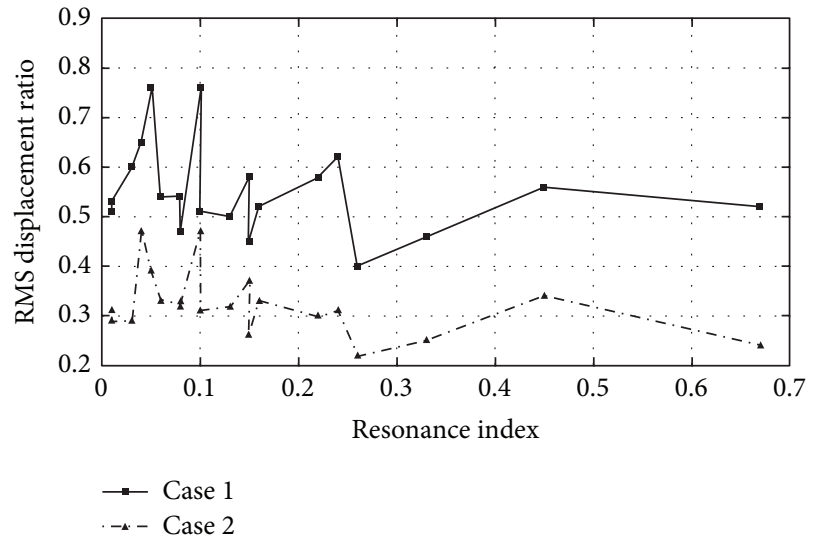

(a)

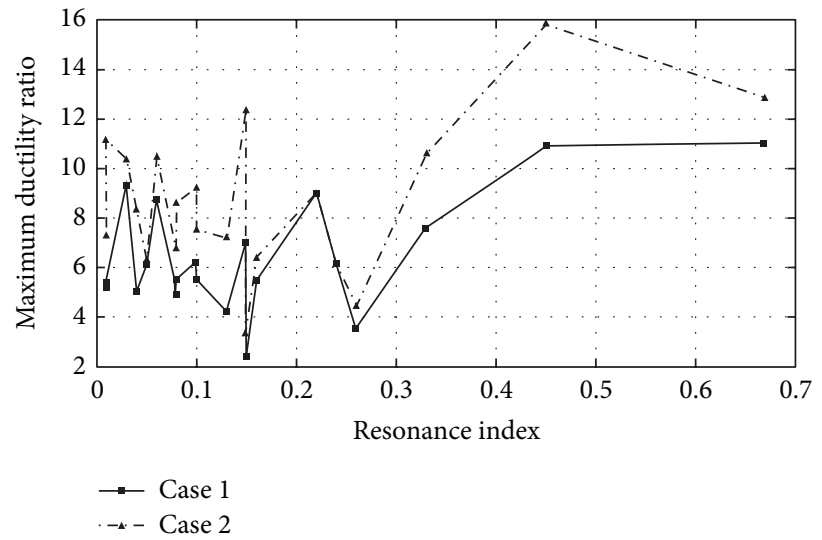

(b)

FIGURE 8: Dependency of (a) damper efficiency and (b) damper maximum ductility ratio on frequency content of the ground motions. Case 1: period $=0.6 \mathrm{~s}$, stiffness ratio $=1$, and yielding force-deck weight ratio $=0.05$. Case 2 : period $=0.6 \mathrm{~s}$, stiffness ratio $=4$, and yielding force-deck weight ratio $=0.10$.

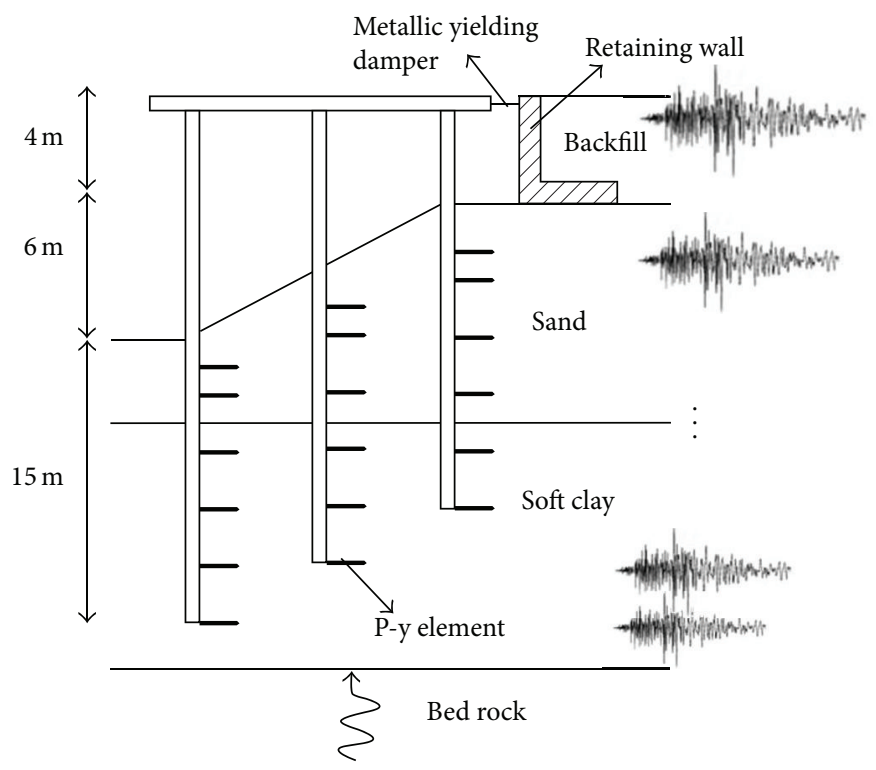

Figure 9: Considered soil-wharf-damper system.

$S_{a}$, it is possible to obtain value of the $S_{a_{\mathrm{eq}}}$ and consequently the equivalent viscous damping. Obviously, the equivalent viscous damping can be used only for preliminary design, and for the final design nonlinear behavior of the damper should be explicitly considered.

\section{Design of the Damper}

A simple retrofit-based design procedure is proposed in this section assuming that the stability condition of the retaining wall cannot be improved. A stable condition for a sheet pile wall would be provided if its safety factors in shear and flexure remain in acceptable ranges. In the case of a gravity wall, stability condition would be provided if the wall has acceptable safety factors against slip and rotation. The authors would like to elaborate that the damper force has no noticeable effect on other failure modes, such as foundation bearing or settlement.

Step 1. Determine the allowable force that the retaining wall can sustain at the damper location during the design earthquake, $R$.

Again it should be clarified that $R$ is a small fraction of redundant capacity of the retaining wall that is provided by its initial safety factor. It is obvious that reduction of the wall safety factor is inevitable, but the value of $R$ can be tuned such that the reduced safety factor still remains in an acceptable range. Clearly, the damper force and other imposed forces on the wall are not necessarily in phase. However, in this design guideline, these forces are assumed to be in phase in favor of 


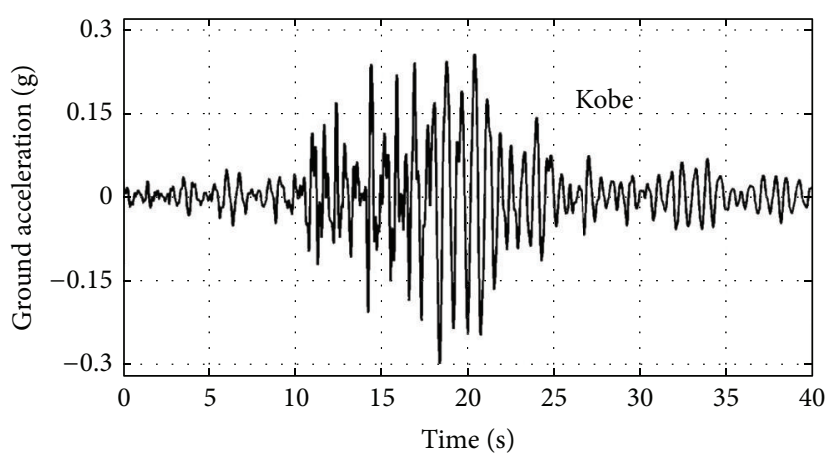

(a)

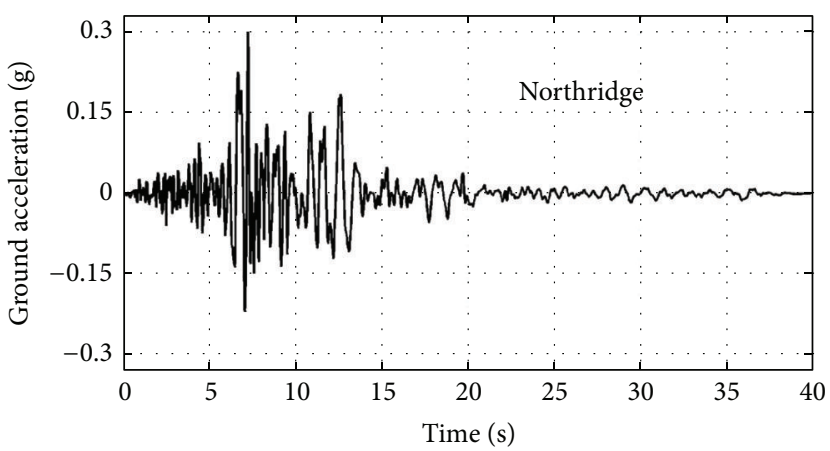

(c)

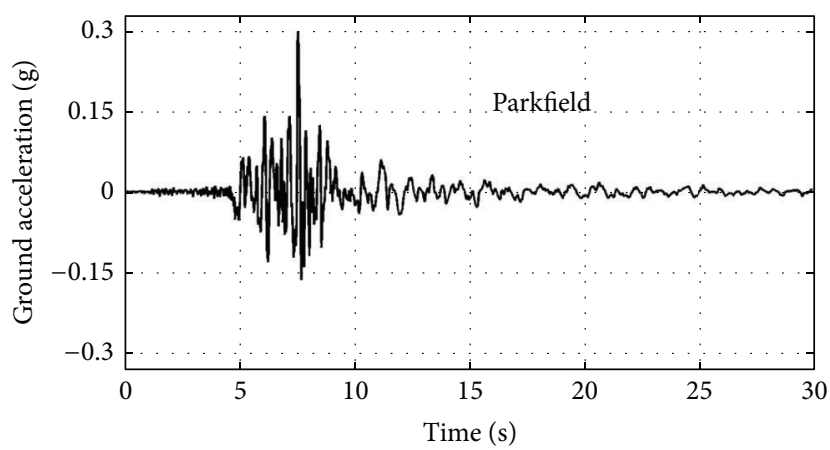

(e)

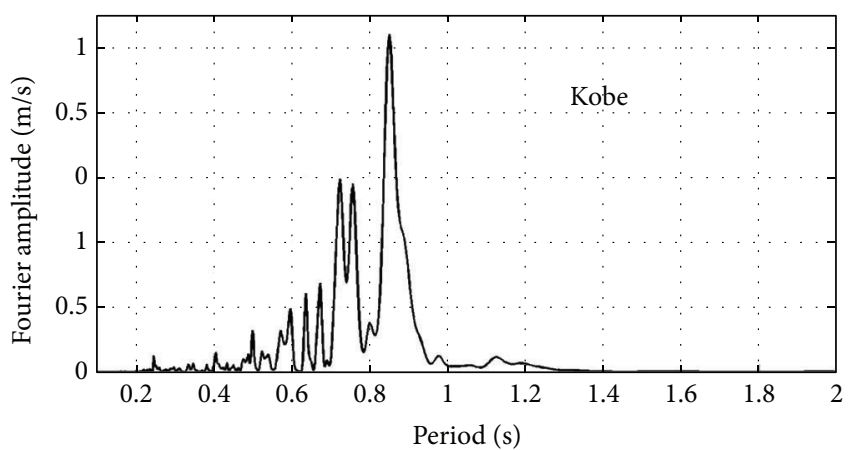

(b)

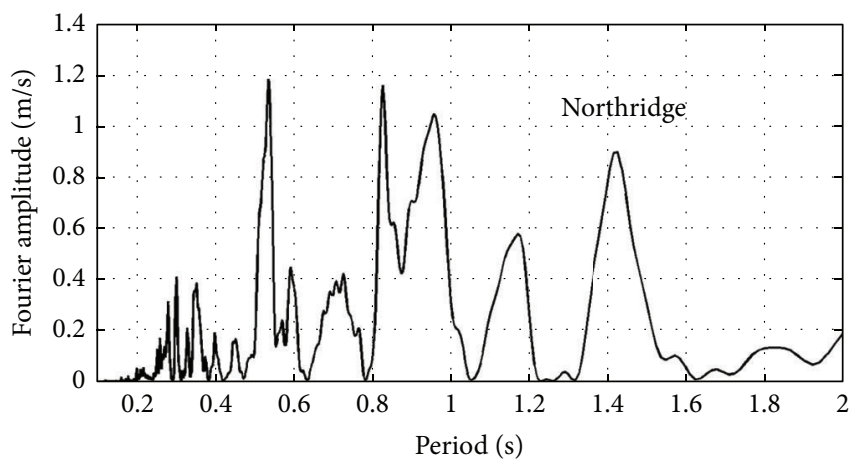

(d)

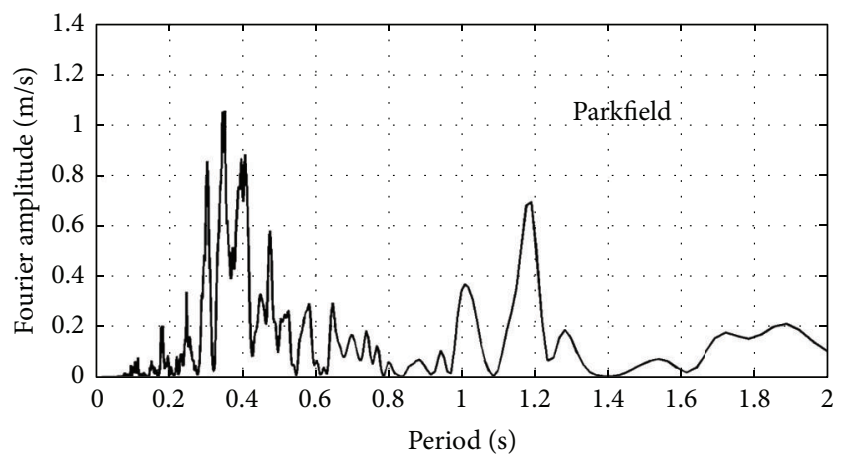

(f)

FIGURE 10: Considered ground accelerations at the rock outcropping and their corresponding Fourier spectra.

safety. A simplified guideline is presented in Section 6.1 for selecting the value of $R$.

Step 2. Determine the yielding force of the damper:

$$
F_{y}=\mathrm{FS} \cdot R
$$

where $F_{y}$ represents yielding force of the damper and FS is an appropriate factor of safety lower than the unity which considers the effect of the damper strain hardening (value of 0.9 is reasonable for FS.)

Step 3. Determine the value of the yielding force-deck weight ratio, $\alpha$ :

$$
\alpha=\frac{F_{y}}{W_{D}},
$$

where $W_{D}$ is the seismic weight of the deck attributed to the damper.

Step 4. Determine the period of the soil-wharf system, $T$.

Step 5. According to (1), evaluate the stiffness ratio, SR, and consequently damper stiffness as follows:

$$
K=\frac{4 \pi^{2} W_{D} \mathrm{SR}}{g T^{2}}
$$

where $g$ and $K$ stand for acceleration of gravity and damper stiffness, respectively.

Step 6. For the preliminary design, according to (2) and (3), estimate the obtained equivalent viscous damping, and for 

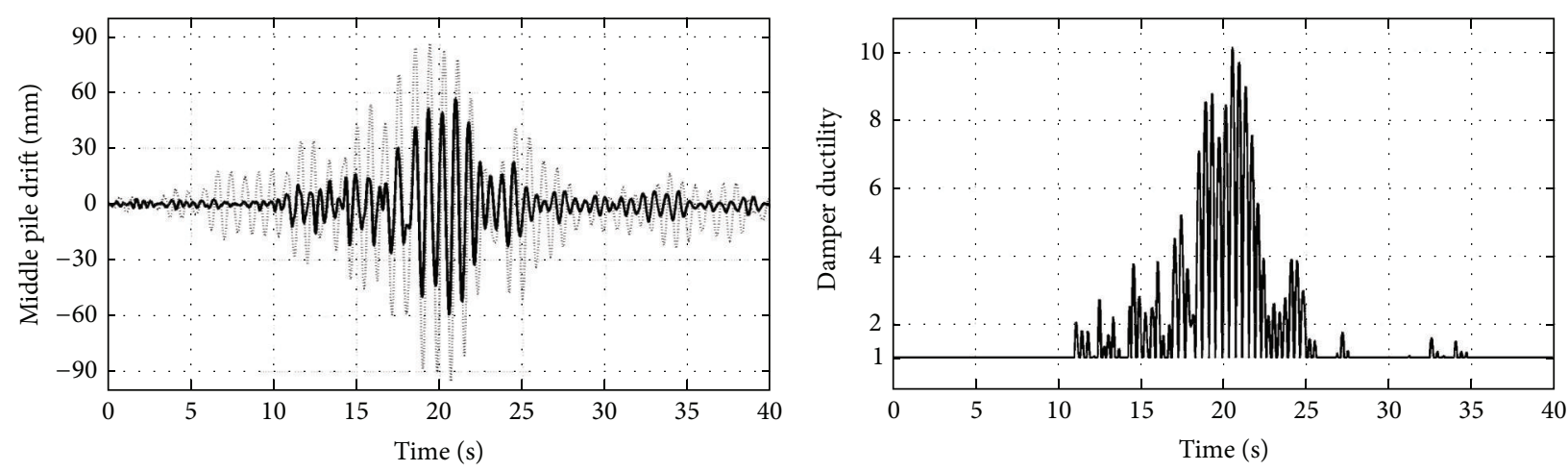

mithout damper

With damper

(a)

(b)

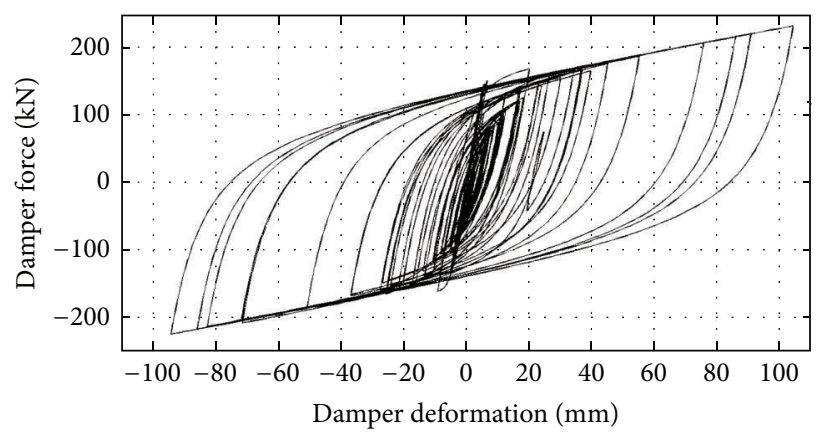

(c)

FIGURE 11: (a) Drift of the middle pile with and without damper, (b) ductility ratio of the damper, and (c) cyclic behavior of the damper-Kobe 1995 earthquake.

the final design use the obtained yielding force (Step 2) and stiffness (Step 5) of the damper in a nonlinear model.

There are some relations in the literature relating stiffness of the yielding damper to its geometrical parameters, such as those proposed by Tehranizadeh [20] for added damping and stiffness devices (ADAS) and those obtained by Soong and Dargush [6] for triangular added damping and stiffness dampers (TADAS). As mentioned earlier, stiffness and yielding displacements of the yielding device are equal to those of the yielding damper due to the rigidity of the damper link.

It should be pointed out that, if the stability condition of the retaining wall can be improved, the design direction would be changed. In this case, according to the desired damping ratio, value of MR can be evaluated first, and then required values of $\alpha$ and SR would be obtained according to (2) and (1), respectively.

6.1. $R$ Selection. A simple yet accurate guideline is presented here to estimate the appropriate value for $R$. Note that all of the presented calculations should be carried out for the most critical section of the wall which experiences the largest forces and has the lowest capacity.
Step 1. Determine shear and flexural (or slip and rotational) capacities of the retaining wall, $C_{v}$ and $C_{f}$, respectively, at the critical section of the wall.

Step 2. Estimate the maximum expected seismic inertial force of the wall, $F_{I}$, the maximum seismic horizontal force from the backfill soil, $F_{s}$, the hydrostatic force, $F_{\mathrm{hs}}$, and the maximum hydrodynamic force, $F_{\text {hd }}$. It should be pointed out that $F_{s}$ and $F_{\text {hd }}$ can be evaluated by many techniques such as Mononobe-Okabe method and Westergaard's theory, respectively [21]. Note that $F_{\mathrm{hs}}$ tends to stabilize the wall while $F_{\text {hd }}$ could have a destructive effect depending on its direction.

Step 3. Estimate the maximum moments at the critical section of the wall due to its inertial force, $M_{I}$, the backfill soil pressure, $M_{s}$, the hydrostatic force, $M_{\mathrm{hs}}$, and the hydrodynamic force, $M_{\mathrm{hd}}$.

Step 4. Determine the acceptable reduced factor of safety, $\mathrm{FS}_{r}$, of the retaining wall which is greater than unity. As stated earlier, reduction of the retaining wall safety factor cannot be avoided. It is clear that this reduction must be in an allowable and reasonable range. In fact just a $10 \%$ reduction is enough for a significant reduction in the wharf response. 

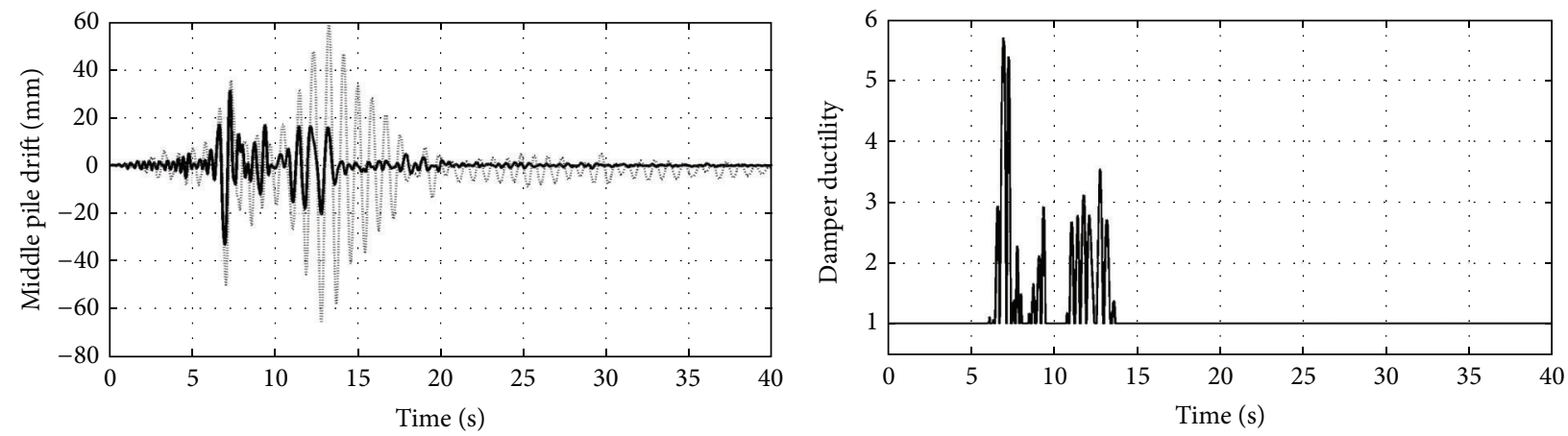

Without damper

— With damper

(a)

(b)

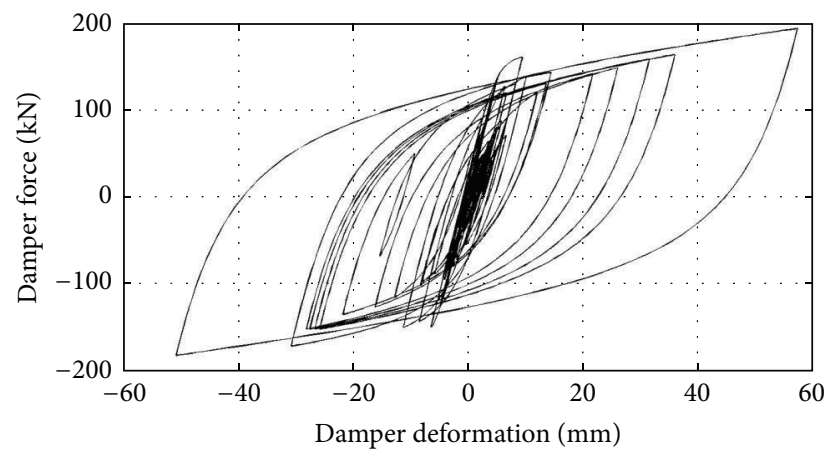

(c)

FIgURE 12: (a) Drift of the middle pile with and without damper, (b) ductility ratio of the damper, and (c) cyclic behavior of the damperNorthridge 1994 earthquake.

Step 5. Select the minimum of $R_{V}$ and $R_{M}$ as the value of $R$. Equation (7) is obtained based on the shear and moment equilibrium of the retaining wall in which $R_{V}$ and $R_{M}$ are the maximum allowable damper forces according to the shear and flexural (or slip and rotationl) capacity of the retaining wall, respectively:

$$
\begin{gathered}
R_{V}=\frac{C_{V}}{\mathrm{FS}_{r}}-F_{I}-F_{S}-F_{\mathrm{hd}}+F_{\mathrm{hs}}, \\
R_{M}=\frac{1}{h}\left(\frac{C_{f}}{\mathrm{FS}_{r}}-M_{I}-M_{S}-M_{\mathrm{hd}}+M_{\mathrm{hs}}\right),
\end{gathered}
$$

where $h$ is the distance between damper-wall connection and the critical section of the wall.

As the height of the wall increases, amounts of its external forces would also increase. Accordingly, the sensitivity of the wall on the damper force would decrease in the cases of higher quay walls.

\section{Numerical Assessment}

Contribution of the proposed damper is evaluated in this section for a typical pile-supported wharf. Effect of the yielding damper on the retaining wall stability is also examined.
Material and geometrical nonlinearities are not considered as structural elements are intended to remain mainly elastic per OCDI [13]. It should be noted that, in this example, soil-pile interaction is considered to examine validity of the optimization assumptions. Soil characteristics are considered based on a real soil profile; however, they are not presented here due to space limitation. As depicted in Figure 9, three steel piles with an outer diameter of $1 \mathrm{~m}$ and wall thickness of $10 \mathrm{~mm}$ are assumed to support the deck. The piles are spaced per $5 \mathrm{~m}$ along the shoreline. Moreover, the adopted deck is a concrete slab with thickness of $0.4 \mathrm{~m}$ and seismic weight of $1600 \mathrm{kN}$. Slab length is $12 \mathrm{~m}$ perpendicular to the shoreline, and its width along the shoreline is assumed to be $5 \mathrm{~m}$. In other words, a $5 \mathrm{~m}$ part of the wharf is separated and considered during this example, and value of $5 \%$ is considered as its inherent first mode damping ratio. It is assumed that the stability condition of the retaining wall in $5 \mathrm{~m}$ intervals is such that $10 \%$ of the deck weight can be considered as the damper yielding force. The effect of this value on the safety factor of the wall will be investigated during this example.

Well-known p-y elements, as suggested by Boulanger et al. [22], are used to simulate soil-pile interaction, and pile group effect is also considered as proposed by Castelli and Maugeri [23]. Moreover, EERA, developed by Bardet 

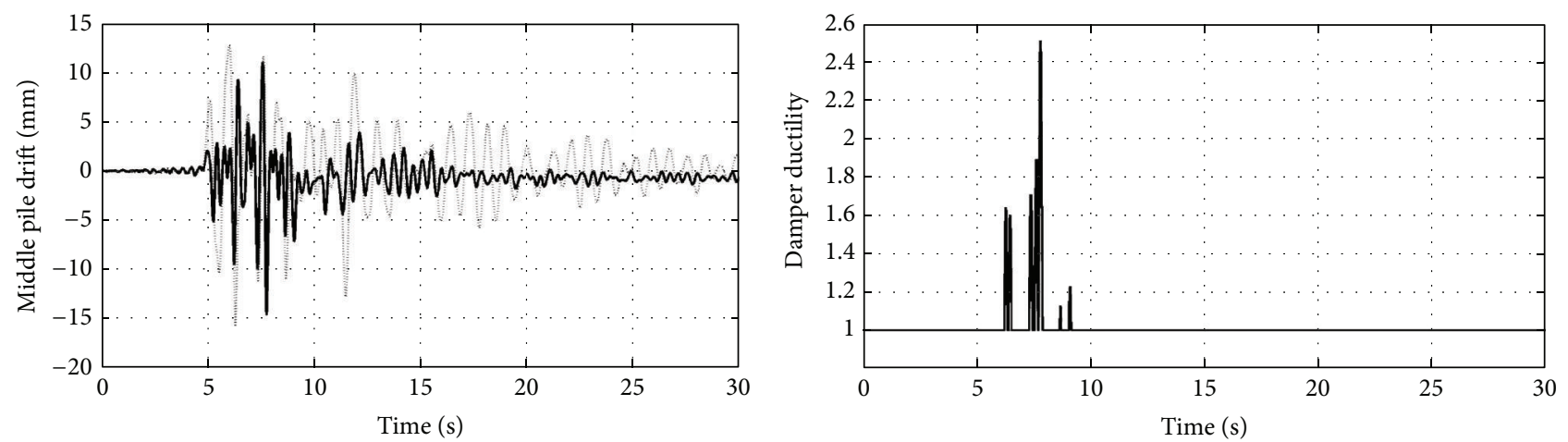

Wumumum Without damper
With damper

(a)

(b)

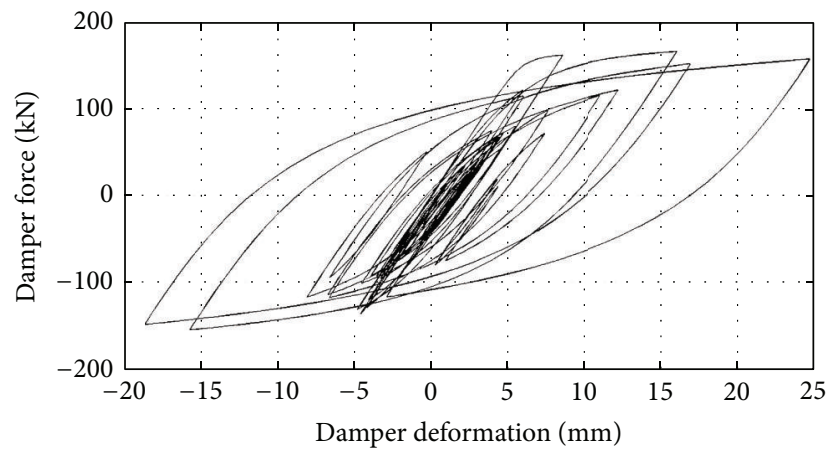

(c)

Figure 13: (a) Drift of the middle pile with and without damper, (b) ductility ratio of the damper, and (c) cyclic behavior of the damperParkfield 1966 earthquake.

TABLE 2: Results of the numerical example.

\begin{tabular}{lccccc}
\hline & \multicolumn{2}{c}{ Without damper } & & \multicolumn{2}{c}{ With damper } \\
Earthquake event & $\begin{array}{c}\text { Maximum middle } \\
\text { pile drift }(\mathrm{cm})\end{array}$ & $\begin{array}{c}\text { RMS middle pile } \\
\text { displacement }(\mathrm{cm})\end{array}$ & $\begin{array}{c}\text { Maximum middle pile } \\
\text { displacement }(\mathrm{cm})\end{array}$ & $\begin{array}{c}\text { RMS middle pile } \\
\text { displacement }(\mathrm{cm})\end{array}$ & $\begin{array}{c}\text { Maximum damper } \\
\text { ductility ratio }\end{array}$ \\
\hline Northridge & 6.62 & 2.76 & 3.35 & 0.99 & 5.7 \\
Parkfield & 1.59 & 0.60 & 1.47 & 0.35 & 2.5 \\
Kobe & 9.51 & 4.99 & 5.94 & 2.51 & 10.1 \\
\hline
\end{tabular}

et al. [24], is used for the required free field response analysis. It should be clarified that $\mathrm{p}-\mathrm{y}$ element technique is a simplified method which cannot directly account for topographic irregularities. Besides, as suggested by OCDI [13], required inputs of this method are the obtained results of the free field analysis which is an equivalent-linear method, and its application is limited to soil strains of $1 \%$ or less.

The fundamental period of the fixed base wharf is $0.43 \mathrm{~s}$, and, by considering the soil-pile interaction, its value would increase to $0.84 \mathrm{~s}$. It is clear that $0.84 \mathrm{~s}$ should be used to estimate optimum parameters of the damper. As a result, in this assessment, $\alpha$ and $T$ are 0.1 and 0.84 , respectively, and SR and MR, respectively, would be 3 and 0.51 . Northridge 1994, Parkfield 1966, and Kobe 1995 ground motions are used in this example. The so-called earthquakes are scaled to $\mathrm{PGA}=0.3 \mathrm{~g}$ at rock outcropping. As shown in Figure 10, these seismic events are adopted due to their difference in the frequency contents at the period of $0.84 \mathrm{~s}$. Note that adopted ground motions are not scaled based on their response spectrum as this assessment intends to examine the resonance effect on the damper contribution as well.

Obviously, for a practical design, these ground motions should be scaled based on an applicable code.

As suggested by Takahashi and Takemura [25], one of the most important reported wharf damages was bending moment on piles due to their large lateral drifts. Therefore, in this example, drift of the middle pile is considered as the response of the structure and is compared in different cases. Figures $11-13$ and Table 2 represent the obtained results. It should be elaborated that the optimum stiffness of the damper is estimated according to (1). It is clear that the damper effectively reduced the response of the wharf and 


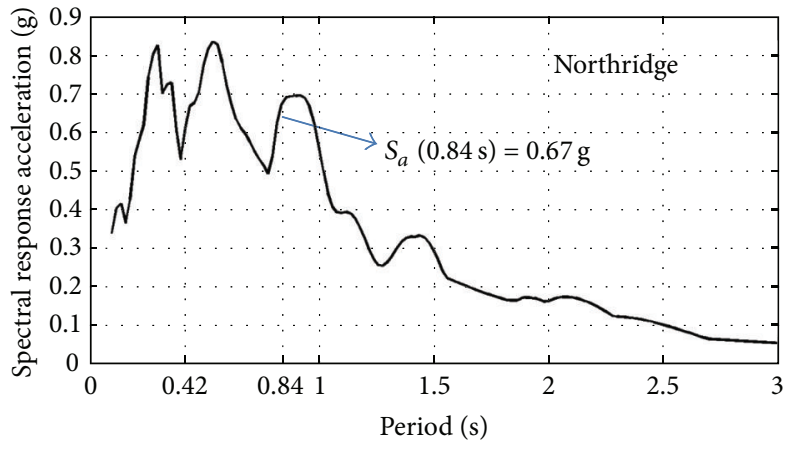

(a)

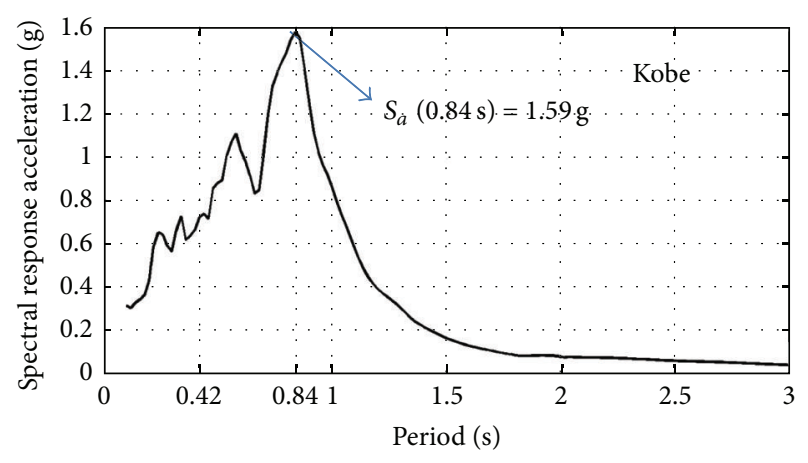

(b)

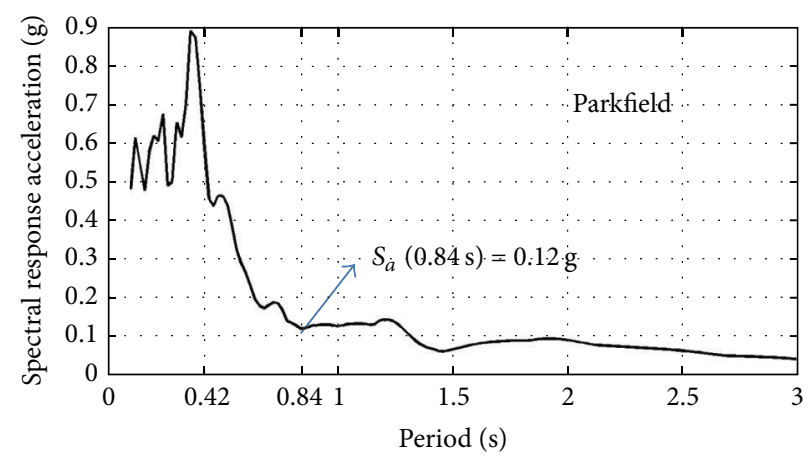

(c)

FIGURE 14: Spectral response accelerations of the considered ground motions.

TABLE 3: Validity of the optimization assumptions.

\begin{tabular}{|c|c|c|c|c|c|}
\hline \multirow{2}{*}{ Earthquake event } & \multirow{2}{*}{ Earthquake intensity } & \multicolumn{2}{|c|}{ Maximum displacement ratio (MR) } & \multicolumn{2}{|c|}{ Maximum ductility ratio } \\
\hline & & Predicted & Observed & Predicted & Observed \\
\hline Northridge & strong & 0.51 & 0.51 & 6 & 5.7 \\
\hline Kobe & Very strong & 0.51 & 0.62 & 6 & 10.1 \\
\hline Parkfield & weak & 0.51 & 0.92 & 6 & 2.5 \\
\hline
\end{tabular}

saved the piles from severe seismic-induced damages, regardless of the resonance condition.

It can be seen from Table 2 that, in the resonance condition, that is, Northridge and Kobe events, the damper effectively reduced both maximum and RMS responses, and the reduction was mainly due to the energy dissipation capability of the damper. However, in the case in which the resonance has not occurred, that is, Parkfield earthquake, the damper was able to reduce only the RMS response mainly through stiffness increasing rather than energy dissipation. This should be considered as the merit of yielding dampers as these devices remain mainly elastic during service level ground motions and localize damages and show noticeable energy dissipation capabilities in the cases of design level earthquakes. In Kobe earthquake, ground acceleration frequencies are concentrated in a narrow band making the earthquake very similar to a harmonic excitation with the resonance frequency. Therefore, the damper sustained large ductility demands during the Kobe ground motion. However this value is still in a safe range. Table 3 represents validity of the optimization assumptions. Parkfield earthquake was a very weak excitation for the considered wharf and is excluded in Table 3. Note that intensities of the earthquakes are evaluated based on their spectral acceleration spectra as shown in Figure 14.

Obtained results indicate that the proposed technique is accurate for design level earthquakes (Northridge earthquake in this case). However the accuracy would be lost for very weak and very strong ground motions.

Friction angle, density, and pore pressure ratio of the backfill soil are assumed to be 30 degree, $1800 \mathrm{~kg} / \mathrm{m}^{3}$, and 0.15 , respectively. Dead and live loads on the backfill soil are $35 \mathrm{kN} / \mathrm{m}^{2}$. Moreover, thickness of the retaining wall is $0.8 \mathrm{~m}$. As a result, the maximum slip force and rotational moment on the wall would be $580 \mathrm{kN}$ and $1110 \mathrm{kN} \cdot \mathrm{m}$ per unit length of the wall, respectively. As illustrated earlier in Figure 12, the maximum damper force in the case of design level earthquake (Northridge earthquake) is only $200 \mathrm{kN}$ for $5 \mathrm{~m}$ length of the wall, that is, $40 \mathrm{kN}$ per unit length, and its corresponding rotational moment is $140 \mathrm{kN} \cdot \mathrm{m}$ per unit length. It is obvious 
TABLE 4: Ground motion records used in the optimization process.

\begin{tabular}{|c|c|c|c|c|c|}
\hline Earthquake & Station name & Comp. & Mag. & PGA $(g)$ & Source \\
\hline Borrego mountain 04/09/68 & El centro array \#9 & 180 & 6.8 & 0.13 & Usgs \\
\hline Borrego mountain $04 / 09 / 68$ & El centro array $\# 9$ & 270 & 6.8 & 0.057 & Usgs \\
\hline Imperial valley $5 / 19 / 40$ & El centro array \#9 & 180 & 7 & 0.313 & Usgs \\
\hline Imperial valley $5 / 19 / 40$ & El centro array \#9 & 270 & 7 & 0.215 & Usgs \\
\hline Kern county $7 / 21 / 52$ & Taft lincoln school & 021 & 7.4 & 0.156 & Usgs \\
\hline Kern county $7 / 21 / 52$ & Taft lincoln school & 111 & 7.4 & 0.178 & Usgs \\
\hline San fernando $02 / 09 / 71$ & La hollywood stor lot & 090 & 6.6 & 0.21 & Usgs \\
\hline San fernando $02 / 09 / 71$ & La hollywood stor lot & 180 & 6.6 & 0.174 & Usgs \\
\hline San fernando 02/09/71 & Lake hughes \#4 & 111 & 6.6 & 0.192 & Usgs \\
\hline San fernando 02/09/71 & Lake hughes \#4 & 201 & 6.6 & 0.153 & Usgs \\
\hline Duzce 11/12/99 & Lamont station 1062 & $\mathrm{~N}$ & 7.1 & 0.114 & Lamont \\
\hline Duzce 11/12/99 & Lamont station 1062 & $\mathrm{E}$ & 7.1 & 0.257 & Lamont \\
\hline Northridge $01 / 17 / 94$ & Canyon country-w lost canyon & 000 & 6.7 & 0.41 & Usc \\
\hline Northridge $01 / 17 / 94$ & Canyon country-w lost canyon & 0270 & 6.7 & 0.482 & Usc \\
\hline Northridge eq 1/17/94 & Lakewood-del amo & 000 & 6.7 & 0.137 & Usc \\
\hline Northridge eq 1/17/94 & Lakewood-del amo & 090 & 6.7 & 0.123 & Usc \\
\hline Parkfield 06/28/66 & Cholame \#5 & 085 & 6.1 & 0.442 & Cdmg \\
\hline Parkfield 06/28/66 & Cholame \#5 & 355 & 6.1 & 0.367 & Cdmg \\
\hline Manjil, Iran & Station code: 18 & ,-N66E & 7.37 & 0.184 & - \\
\hline Manjil, Iran & Station code: 18 & ,-N24W & 7.37 & 0.131 & - \\
\hline
\end{tabular}

that the maximum damper force is much smaller than that imposed from other sources.

If initial safety factor of the wall was assumed to be 1.5 , the reduced safety factor would be about 1.33 . Therefore by $11 \%$ reduction in the initial safety factor of the retaining wall, maximum response of the wharf would be decreased by $49 \%$. In other words, the proposed damper would shift the safety factor from the retaining wall to the piles which are more vulnerable elements. Again it should be clarified that different forces are not necessarily in-phase, and the real reduced safety factor of the wall would be larger than 1.33 and closer to its initial value.

\section{Conclusions}

Through this study contribution of yielding damper on reducing seismic-induced responses of pile-supported wharves was examined. Different parameters of the proposed yielding damper were also optimized. Obtained results indicate that yielding damper can dissipate a considerable portion of the input energy and effectively suppress pile drifts and save them from serious damages during seismic events. Yielding damper has a minor destructive effect on the retaining wall, and selecting an appropriate value for its yielding force is a crucial task. In general, it was shown that the optimum parameters of the damper depend on the retaining wall stability condition, period of the soil-wharf system, and allowable maximum ductility ratio of the damper.

As stated earlier, the damper would inevitably reduce the safety factor of the retaining wall, but this reduction is very small and can be neglected. For example, in the presented numerical example, this reduction was about $11 \%$, and the reduction in response of the wharf was about $50 \%$. In other words, yielding dampers slightly reduce the safety factor of the retaining wall, whereas effectively increase safety factor of the piles which are much more vulnerable to seismic excitations. It should be pointed out that the socalled destructive effect would be smaller in the case of higher retaining walls. The numerical example also indicates that metallic yielding dampers can effectively suppress RMS response of pile-supported wharves during any kind of ground motion regardless of its intensity.

It should be noted that, according to the optimization assumptions and damper placement, flexible wharves with solid retaining walls are the best options for the presented technique. This technique is not recommended for wharves with weak retaining walls due to the used philosophy, that is, shifting the safety factor from the wall to the wharf piles.

The authors would like to elaborate that there are still some unanswered questions about the proposed technique that call for further studies. For example, if the wall-soil system behind the wharf was very soft, some of the adopted optimization assumptions may not be valid anymore. Besides, as suggested during the paper, imposed damper force on the retaining wall is out of phase with other forces, and this feature can be formulated in other studies. Consideration of this effect would decrease the destructive effect of the proposed technique on the retaining wall.

\section{Appendix}

Ground motion records that were used in the optimization process are presented in Table 4. 


\section{References}

[1] N. Gerolymos, A. Giannakou, I. Anastasopoulos, and G. Gazetas, "Evidence of beneficial role of inclined piles: observations and summary of numerical analyses," Bulletin of Earthquake Engineering, vol. 6, no. 4, pp. 705-722, 2008.

[2] H. G. Poulos, "Raked piles-virtues and drawbacks," Journal of Geotechnical and Geoenvironmental Engineering, vol. 132, no. 6, pp. 795-803, 2006.

[3] D. Oyenuga, E. Abrahamson, A. Krimotat, A. Kozak, T. Labasco, and F. Lobedan, "A study of the pile-wharf deck connection at the Port of Oakland," in Ports 2001: American's Ports-Gateways to the Global Economy, 2004.

[4] D. E. Lehman, E. Brackmann, A. Jellin, and C. W. Roeder, "Seismic performance of pile-wharf connections," in Proceedings of the ASCE Technical Council on Lifeline Earthquake Engineering Conference (TCLEE '09), p. 84, Oakland, Calif, USA, July 2009.

[5] D. Mageau and K. Chin, "Effectiveness of stone columns on slope deformations beneath wharves," in Proceedings of the ASCE Technical Council on Lifeline Earthquake Engineering Conference (TCLEE '09), p. 94, Oakland, Calif, USA, July 2009.

[6] T. T. Soong and G. Dargush, Passive Energy Dissipation Systems in Structural Engineering, Wiley, Chichester, UK, 1997.

[7] C. Xia and R. D. Hanson, "Influence of ADAS element parameters on building seismic response," Journal of Structural Engineering, vol. 118, no. 7, pp. 1903-1918, 1992.

[8] D. Foti, L. Bozzo, and F. Lopez-Almansa, "Numerical efficiency assessment of energy dissipaters for seismic protection of buildings," Earthquake Engineering and Structural Dynamics, vol. 27, pp. 543-556, 1998.

[9] L. M. Moreschi and M. P. Singh, "Design of yielding metallic and friction dampers for optimal seismic performance," Earthquake Engineering and Structural Dynamics, vol. 32, no. 8, pp. 12911311, 2003.

[10] F. C. Ponzo, A. di Cesare, D. Nigro et al., "JET-PACS project: dynamic experimental tests and numerical results obtained for a steel frame equipped with hysteretic damped chevron braces," Journal of Earthquake Engineering, vol. 16, pp. 662-685, 2012.

[11] I. Towhata, M. J. Alam, T. Honda, and S. Tamate, "Model tests on behaviour of gravity-type quay walls subjected to strong shaking," Bulletin of the New Zealand Society for Earthquake Engineering, vol. 42, no. 1, pp. 47-56, 2009.

[12] A. Sadrekarimi, A. Ghalandarzadeh, and J. Sadrekarimi, "Static and dynamic behavior of hunchbacked gravity quay walls," Soil Dynamics and Earthquake Engineering, vol. 28, no. 2, pp. 99-117, 2008.

[13] OCDI, Technical Standards and Commentaries for Port and Harbor Facilities in Japan, The Overseas Coastal Area Development Institute of Japan, Tokyo, Japan, 2002.

[14] PEER, Strong Ground Motion Database, 2009, http://peer .berkeley.edu/smcat/.

[15] S. Mazzoni, F. McKenna, M. H. Scott, and G. L. Fenves, The OpenSees Command Language Manual: Version 1.7.3, Pacific Earthquake Engineering Center, University of California, Berkeley, Calif, USA, 2006.

[16] S. A. Mousavi, K. Bargi, and S. M. Zahrai, "Optimum parameters of tuned liquid column-gas damper for mitigation of seismic-induced vibrations of offshore jacket platforms," Structural Control and Health Monitoring, vol. 20, no. 3, pp. 422-444, 2013.

[17] Matlab, User Guide, Curve Fitting Toolbox, MathWorks Inc., Version 7.6.0, 2008.
[18] Applied Technology Council (ATC), "Seismic evaluation and retrofit of concrete buildings," Tech. Rep. ATC 40, Applied Technology Council, Redwood City, Calif, USA, 1996.

[19] ASCE, Prestandard and Commentary for the Seismic Rehabilitation of Buildings (FEMA356), Federal Emergency Management Agency, Washington, DC, USA, 2000.

[20] M. Tehranizadeh, "Passive energy dissipation device for typical steel frame building in Iran," Engineering Structures, vol. 23, no. 6, pp. 643-655, 2001.

[21] S. L. Kramer, Geotechnical Earthquake Engineering, Prentice Hall, Englewood Cliffs, NJ, USA, 1996.

[22] R. W. Boulanger, C. J. Curras, B. L. Kutter, D. W. Wilson, and A. Abghari, "Seismic soil-pile-structure interaction experiments and analyses," Journal of Geotechnical and Geoenvironmental Engineering, vol. 125, no. 9, pp. 750-759, 1999.

[23] F. Castelli and M. Maugeri, "Simplified approach for the seismic response of a pile foundation," Journal of Geotechnical and Geoenvironmental Engineering, vol. 135, no. 10, pp. 1440-1451, 2009.

[24] J. P. Bardet, K. Ichii, and C. H. Lin, A Computer Program for Equivalent-Linear Earthquake Site Response Analyses, Department of Civil Engineering, University of Southern California, 2000.

[25] A. Takahashi and J. Takemura, "Liquefaction-induced large displacement of pile-supported wharf," Soil Dynamics and Earthquake Engineering, vol. 25, no. 11, pp. 811-825, 2005. 

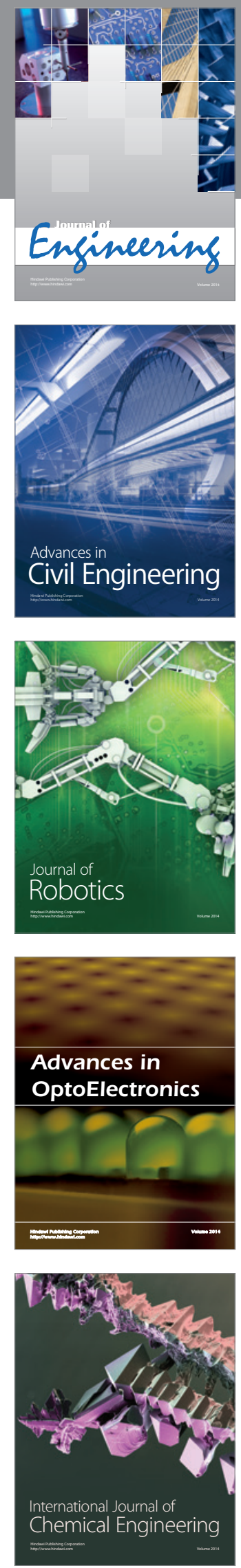

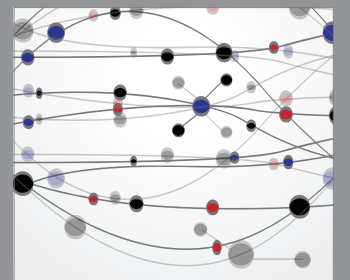

The Scientific World Journal
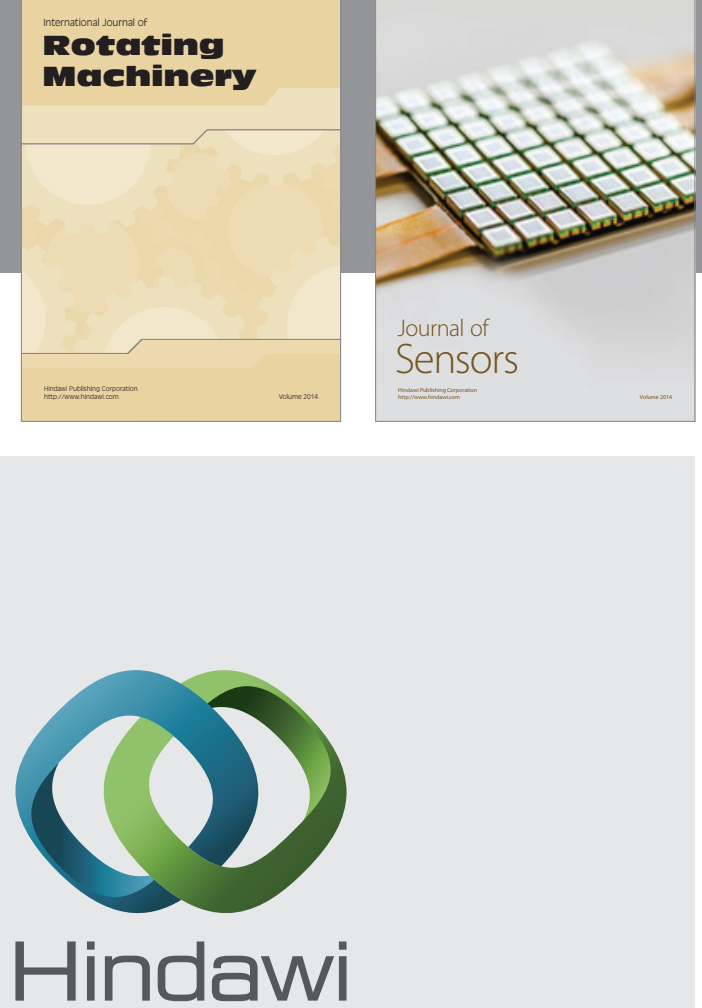

Submit your manuscripts at http://www.hindawi.com
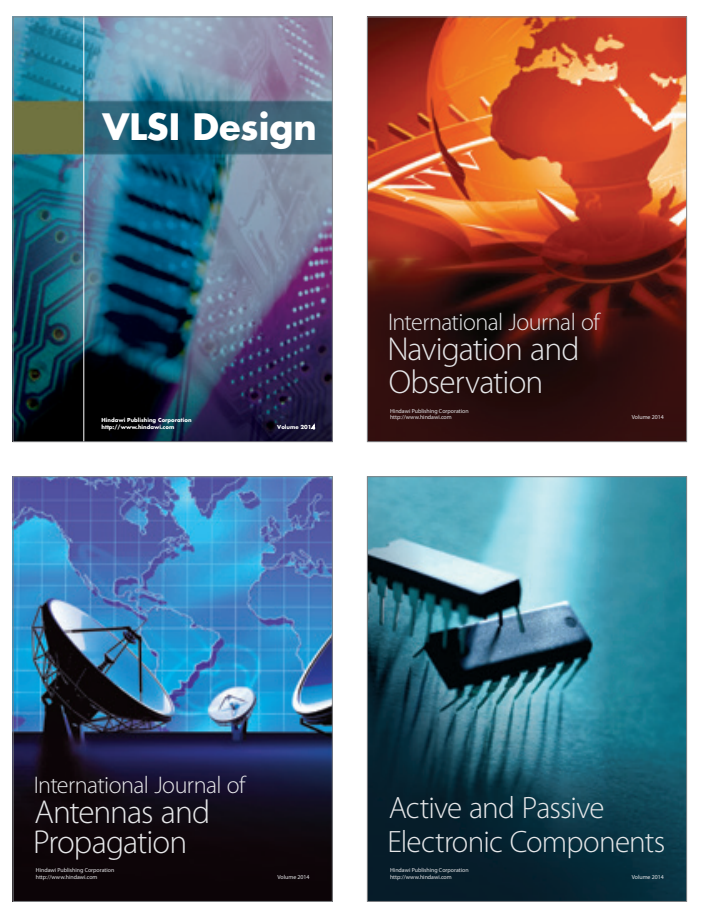
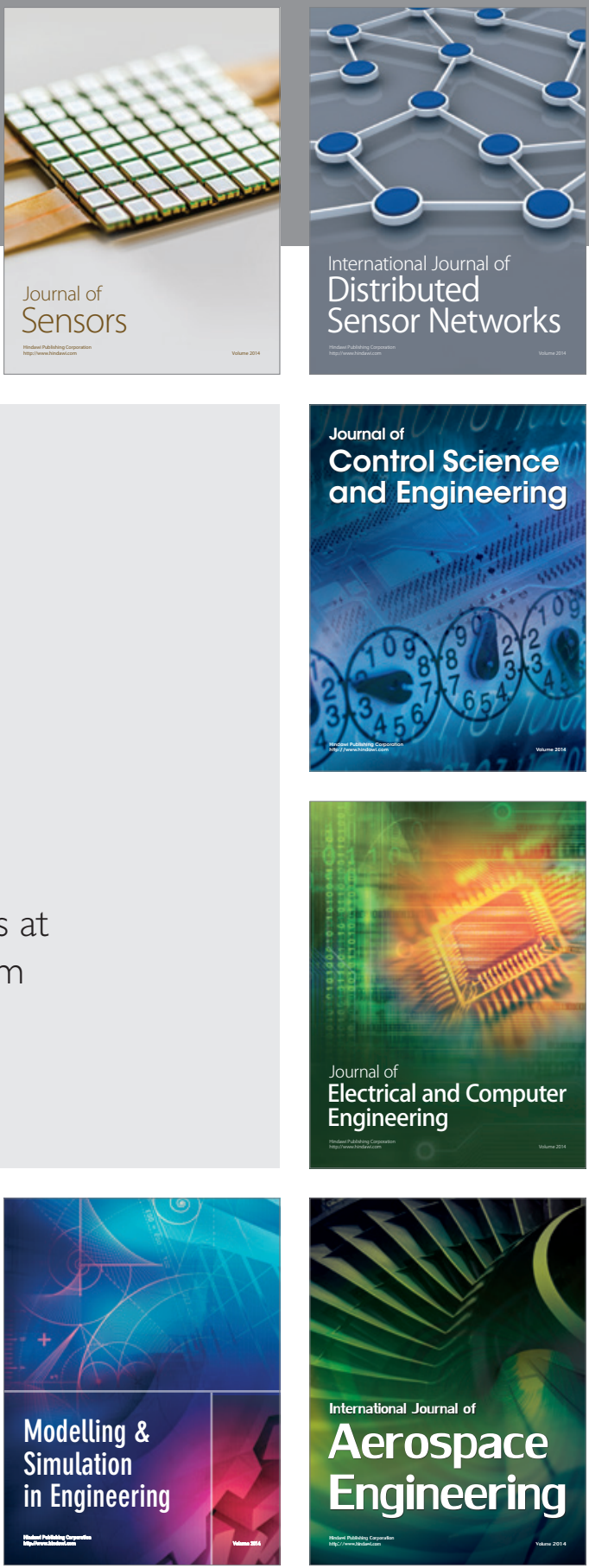

Journal of

Control Science

and Engineering
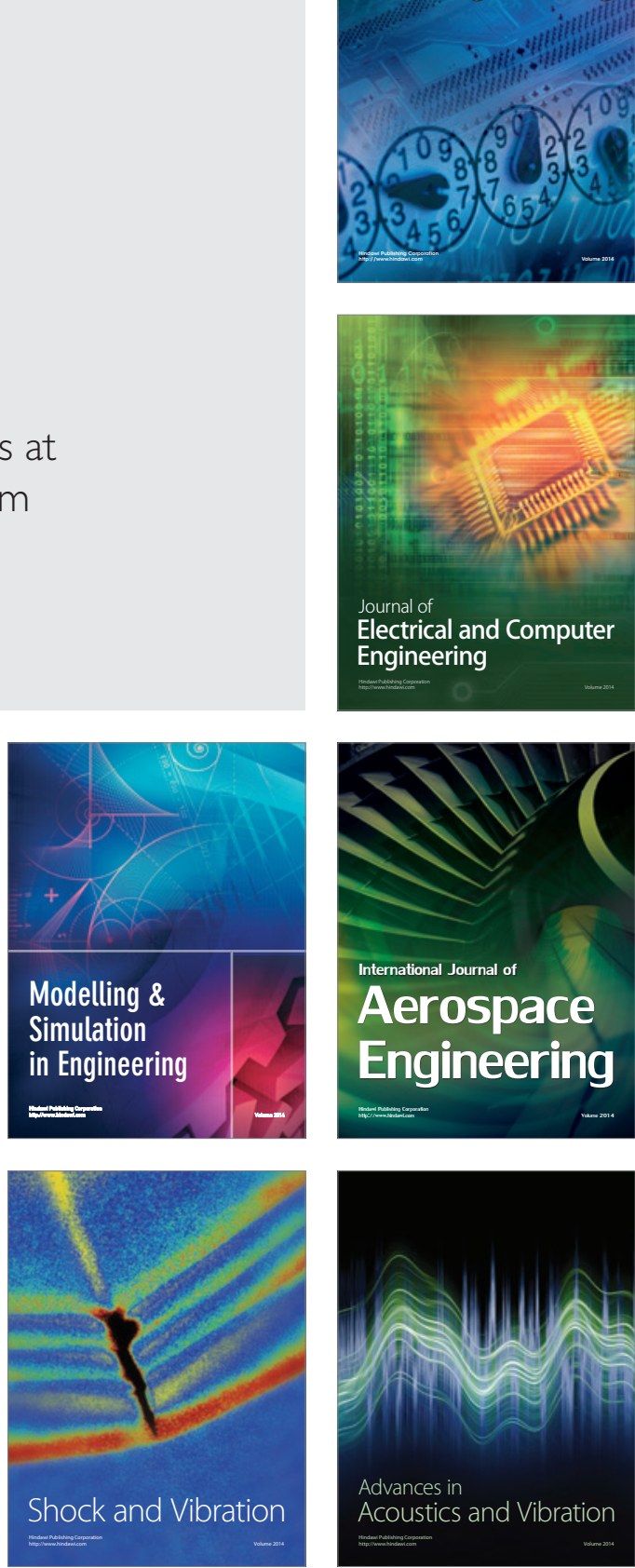